AGRICA: Journal of Sustainable Drayland Agriculture, 14 (1): 83-90 (2021)

ISSN-Online: 2715-4955; ISSN-Cetak: 2715-6613

DOI: https://doi.org/10.37478/agr.v14i1.1061

\title{
EFEKTIFITAS PENGGUNAAN CENDAWAN MIKORIZA TERHADAP PERTUMBUHAN BIBIT KAKAO SAMBUNG PUCUK (Theobroma cacao L.) DI KABUPATEN SIKKA
}

\author{
Yovita Yasintha Bolly ${ }^{1}$, Yuyun Wahyuni ${ }^{2}$ \\ Program Studi Agroteknologi Fakultas Pertanian Universitas Nusa Nipa \\ Jln. Kesehatan No. 03, Alok Timur, Sikka, Nusa Tenggara Timur \\ Email : vytayovieeta@gmail.com
}

\begin{abstract}
The Effectiveness of the Use Of Mycoriza On The Growth Of Cacao Seeds (Theobroma cacao L.) in Sikka District. The use of mycorrhizal biofertilizers in shoot grafting cacao (Theobroma cacao L.) nurseries is one of the efforts made to increase cocoa growth in Sikka Regency. This study aims to determine the effect of the dose of mycorrhizal biological fertilizer on the growth of cocoa seedlings. The study used a randomized block design (RBD) with fertilizer doses of $0 \mathrm{~g} /$ polybag (control), $10 \mathrm{~g} /$ polybag, $20 \mathrm{~g} / \mathrm{polybag}, 30 \mathrm{~g} / \mathrm{polybag}, 40 \mathrm{~g} / \mathrm{polybag}$ $50 \mathrm{~g} /$ polybag. The results showed that the treatment the addition of mycorrhizae on shoot grafting cocoa seedlings had no effect on all growth variables observed at 30 days after mycorrhizal application and significantly affected all growth variables for cacao seedlings aged 60 days after mycorrhizal application. Giving mycorrhizae to shoot grafting cocoa seedlings at a dose of $50 \mathrm{~g} /$ polybag (M5) gave the highest yield for all growth variables of cocoa seedlings aged 60 days after mycorrhizal application, namely plant height $48.50 \mathrm{~cm}$, stem diameter 1.10 $\mathrm{cm}$, and number of leaves 8,25 strands.
\end{abstract}

Keywords: Cacao seeds, Growth, Mycorrhizae, Shoot grafting

\section{PENDAHULUAN}

Kakao (Theobroma cacao L.) merupakan salah satu tanaman perkebunan yang mempunyai peran penting dalam perekonomian. Perkebunan kakao mampu menyediakan lapangan pekerjaan, sumber pendapatan dan salah satu penyumbang devisa negara. Kakao banyak dibudidayakan di Kabupaten Sikka dan menjadi salah satu komoditi unggulan. Dalam membudidayakan kakao petani mengalami berbagai kendalakendala yang mempengaruhi produksi.

Salah satu faktor yang diduga menjadi penyebab rendahnya produktivitas kakao, diantaranya adalah faktor usia tanaman kakao yang sudah tua. Kondisi tanaman kakao yang sudah tua tersebut harus segera dilakukan peremajaan dengan tujuan meningkatkan produktivitas tanaman kakao. Faktor utama lainnya yang diduga 
menyebabkan rendahnya produktivitas kakao adalah kualitas bibit yang kurang baik (Goenadi, 2005; Baharudin dan Rubiyo, 2013).

Saat ini petani lebih banyak memperoleh bibit kakao secara generatif atau melalui biji. Keuntungan perbanyakan kakao secara generatif adalah mudah dan sederhana untuk dilakukan (Wahyudi et al., 2008) serta dapat menghasilkan bibit dalam jumlah banyak dengan pertumbuhan yang seragam serta memiliki perakaran yang kuat. Bibit tanaman hasil perbanyakan generatif memiliki sifat genetik yang bervariasi. Hal ini disebabkan kakao merupakan tanaman yang melakukan penyerbukan silang (cross pollination) dan bunga kakao bersifat protogini yang artinya putik masak lebih awal dari pada kepala sari sehingga serbuk sari tidak mampu membuahi putik dari kuntum yang sama (Prawoto, 2008). Salah satu alternatif yang dapat digunakan untuk menghasilkan bibit yang seragam secara genetik adalah dengan cara perbanyakan bibit secara vegetatif yaitu sambung pucuk.

Teknologi sambung pucuk pada tanaman kakao merupakan penggabungan dua individu klon tanaman kakao yang berbeda menjadi satu dan tumbuh menjadi tanaman baru (Akbar et al., 2017). Teknologi ini menggunakan bibit kakao sebagai batang bawah yang disambung dengan entres dari kakao unggul sebagai batang atas. Bibit batang bawah yang siap disambung adalah pada umur 2,5 sampai 3 bulan (Limbongan dan Djufry, 2013 dalam Akbar et al., 2017). Bibit hasil sambung pucuk akan siap dipindahkan ke lahan setelah berumur 7 bulan (Wahyudi et al., 2008).

Penggunaan bibit sambung pucuk akan menghasilkan tanaman kakao yang sifat genetisnya memiliki keunggulan yaitu kokoh, perakaran kuat, cepat berbuah, produktif, tahan penyakit dan mutu buah baik sesuai dengan sifat genetis induknya sehingga meningkatkan peluang hasil yang optimal (Limbongan dan Fadjry, 2013; Sribawanti Putu et al., 2016;). Tanaman kakao hasil sambung pucuk memerlukan nutrisi untuk dapat tumbuh dan berproduksi dengan baik. Untuk itu kegiatan pemupukan perlu dilakukan untuk menambah ketersediaan unsur hara, baik hara makro atau hara mikro. Salah satu jenis pupuk yang dapat dimanfaatkan yaitu pupuk organik hayati mikoriza. Mikoriza adalah salah satu kelompok cendawan yang hidup di dalam tanah yang mempunyai struktur hifa sebagai tempat kontak dan transfer hara mineral antara jamur dan tanaman inangnya pada jaringan korteks akar. Mikoriza terbentuk karena adanya simbiosis mutualisme antara 
Bolly: Efektifitas penggunaan cendawan mikoriza terhadap pertumbuhan bibit kakao

cendawan atau cendawan dengan sistem perakaran tumbuhan.

Cendawan mikoriza dapat bersimbiosis dengan sebagian besar $(97 \%)$ famili tanaman, seperti tanaman pangan, hortikultura, kehutanan, perkebunan dan tanaman pakan. CMA berpotensi besar sebagai pupuk hayati karena salah satu mikroorganisme yang memiliki peranan sangat penting bagi tanaman seperti dapat memfasilitasi penyerapan unsur hara dalam tanah sehingga dapat meningkatkan pertumbuhan tanaman, sebagai penghalang biologis terhadap infeksi patogen akar, meningkatkan ketersediaan air bagi tanaman dan meningkatkan hormon pemacu tumbuh tanaman (Wirawan, 2014).

Penambahan mikoriza pada pembibitan kakao sambung pucuk diharapkan dapat meningkatkan pertumbuhan dan produksi tanaman kakao. Hal ini didasarkan atas beberapa hasil penelitian menunjukkan bahwa CMA meningkatkan pertumbuhan beberapa bibit tanaman. Hasil penelitian pada bibit jarak pagar menunjukkan bahwa inokulasi Glomus sp meningkatkan pertumbuhan tinggi, diameter, dan bobot kering bibit yang berumur tiga bulan berturut-turut dibandingkan dengan kontrol (Irianto, 2009). Selain itu, cendawan mikoriza diketahui berinteraksi positif dengan bahan organik di dalam tanah, termasuk pada lahan-lahan bermasalah seperti lahan yang mengalami cekaman kekeringan (Nurbaity et al., 2007), termasuk di Kabupaten Sikka. Sehingga penelitian ini perlu dilakukan untuk mengetahui pengaruh dosis pupuk mikoriza terhadap pertumbuhan bibit kakao sambung pucuk.

\section{METODELOGI}

Penelitian ini berlangsung pada bulan Juni sampai September 2020, di Desa Lusitada Kecamatan Nita, Kabupaten Sikka. Mikoriza berasal dari laboratorium pertanian Universitas Brawijaya Malang. Bibit kakao yang digunakan dalam penelitian ini adalah bibit kakao yang berumur 2 bulan setelah sambung pucuk. Bibit diperoleh dari lokasi pembibitan kakao Dinas Pertanian Kabupaten Sikka.

Rancangan penelitian yang digunakan adalah Rancangan Acak Kelompok (RAK) satu faktor dengan 6 perlakuan dan 4 ulangan yaitu $\mathrm{M}_{0}$ : $0 \mathrm{~g} /$ polybag (kontrol), $\mathrm{M}_{1}: 10$ g/polybag, $\quad \mathbf{M}_{2}: 20$ g/polybag, $\quad \mathbf{M}_{3}: 30$ g/polybag, $\mathbf{M}_{4}: 40$ g/polybag dan $\mathrm{M}_{5}: 50$ g/polybag .

Aplikasi mikoriza pada media tanam yaitu saat pemindahan bibit kakao dari polybag pembibitan awal ke polybag penelitian yang telah disiapkan. Media tanam dibasahi kemudian spora mikoriza 
ditaburkan sekitar perakaran bibit kakao. Variabel penelitian yang diamati yaitu tinggi tanaman, jumlah daun dan diameter batang umur 30 hst dan 60 hst.

\section{HASIL DAN PEMBAHASAN}

Hasil pengamatan pertumbuhan bibit kakako sambung pucuk umur 30 hst yang diperoleh pada penelitian ini dapat diihat pada tabel di bawah.

Tabel 1. Pengamatan Pertumbuhan Bibit Kakao Umur 30 HST Aplikasi Mikoriza

\begin{tabular}{cccc}
\hline Perlakuan & $\begin{array}{c}\text { Tinggi Tanaman } \\
(\mathrm{cm})\end{array}$ & $\begin{array}{c}\text { Diameter Batang } \\
(\mathrm{cm})\end{array}$ & $\begin{array}{c}\text { Jumlah Daun } \\
\text { (helai) }\end{array}$ \\
\hline M0 & 45,00 & 0,70 & 2,75 \\
M1 & 45,00 & 0,78 & 4,00 \\
M2 & 45,00 & 0,73 & 2,75 \\
M3 & 47,00 & 0,83 & 2,75 \\
M4 & 45,50 & 0,80 & 3,50 \\
M5 & 45,25 & 0,85 & 4,00 \\
\hline
\end{tabular}

Pengamatan pertama pada penelitian menunjukkan bahwa perlakuan dalam penelitian ini tidak berpengaruh nyata terhadap semua variabel pengamatan pertumbuhan bibit kakao umur 30 hari setelah aplikasi mikoriza. Hal ini diduga karena dalam jangka waktu 30 hari, mikoriza masih dalam proses penetrasi perakaran bibit kakao, sehingga mikoriza belum berpengaruh dalam pertumbuhan tanama. Hal tersebut sejalan dengan penelitian Sugiarti dan Taryana (2018) bahwa pemberian inokulan mikoriza pada tanaman kopi memerlukan waktu lebih dari 4 bulan untuk meningkatkan pertambahan jumlah daun tanaman kopi. Parapasan dan Gusta (2014) menambahkan bahwa waktu aplikasi mikoriza yang tepat adalah saat bibit mulai mengeluarkan akar, dan cara aplikasi yang lebih tepat adalah inokulan mikoriza diletakkan di sekitar perakaran bibit, sehingga mikoriza dapat lebih cepat bersimbiosis dengan akar tanaman.

Menurut Soenartiningsih (2013), proses infeksi dimulai dengan perkecambahan spora di dalam tanah. Hifa yang tumbuh melakukan penetrasi ke dalam akar dan berkembang di dalam korteks. Pada akar yang terinfeksi akan terbentuk arbuskular, vesikel, hifa internal, di antara sel-sel korteks dan hifa eksternal. Penetrasi hifa dan perkembangannya biasa terjadi pada bagian yang masih mengalami proses diferensiasi dan proses pertumbuhan. Pada penelitian Parapasan dan Gusta (2014) menunjukkan bahwa mikoriza yang 
Bolly: Efektifitas penggunaan cendawan mikoriza terhadap pertumbuhan bibit kakao

diaplikasikan pada bibit kopi akan mengeluarkan hifa yang akan menginfeksi akar tanaman.

\section{Pengamatan Pertumbuhan Bibit Kakao}

Hasil pengamatan pertumbuhan bibit kakako sambung pucuk umur 60 hst yang diperoleh pada penelitian ini dapat diihat pada tabel di bawah.

\section{Umur 60 hst aplikasi mikoriza}

Tabel 2. Pengamatan Pertumbuhan Bibit Kakao Umur 60 hst Aplikasi Mikoriza

\begin{tabular}{cccc}
\hline Perlakuan & Tinggi Tanaman $(\mathrm{cm})$ & $\begin{array}{c}\text { Diameter Batang } \\
(\mathrm{cm})\end{array}$ & $\begin{array}{c}\text { Jumlah Daun } \\
\text { (helai) }\end{array}$ \\
\hline M0 & $45,50 \mathrm{a}$ & $0,83 \mathrm{a}$ & $5,25 \mathrm{a}$ \\
M1 & $46,00 \mathrm{~b}$ & $0,90 \mathrm{a}$ & $7,25 \mathrm{c}$ \\
M2 & $45,50 \mathrm{a}$ & $0,95 \mathrm{~b}$ & $5,25 \mathrm{a}$ \\
M3 & $46,25 \mathrm{~b}$ & $1,00 \mathrm{~b}$ & $6,25 \mathrm{~b}$ \\
M4 & $47,75 \mathrm{c}$ & $1,00 \mathrm{~b}$ & $7,00 \mathrm{c}$ \\
M5 & $48,50 \mathrm{~d}$ & $1,10 \mathrm{~b}$ & $8,25 \mathrm{~d}$ \\
\hline
\end{tabular}

Keterangan: huruf yang berbeda pada kolom yang sama, berbeda nyata pda BNT 5\%.

Aplikasi mikoriza memberikan pengaruh yang nyata terhadap semua variabel pengamatan pertumbuhan bibit kakao sambung pucuk pada 60 hari setelah aplikasi mikoriza. Perlakuan M5 memberikan hasil tertinggi pada tinggi tanaman sebesar $48,50 \mathrm{~cm}$, diameter batang $1,10 \mathrm{~cm}$, dan jumlah daun 8,25 helai, sedangkan hasil terendah diperoleh pada perlakuan M0 yaitu tinggi tanaman sebesar $45,50 \mathrm{~cm}$, diameter batang sebesar $0,83 \mathrm{~cm}$ dan jumlah daun sebesar 5,25 helai.

Secara keseluruhan pada pengamatan kedua, hasil terbaik terdapat pada perlakuan M5 dengan dosis mikoriza sebanyak 50 g/polybag. Hal ini diduga semakin bayak hifa mikoriza yang menginfeksi akar tanaman akan meningkatkan kinerja mikoriza dalam penyerapan unsur hara oleh bibit kakao sambung pucuk. Parapasan dan Gusta (2014) berpendapat bahwa tingginya infeksi akar pada perlakuan aplikasi ganda (diberikan saat deder biji dan pindah tanam bibit) diduga akibat hifa yang melakukan penetrasi ke dalam akar lebih banyak, sehingga semakin meningkatkan pertumbuhan hifa di dalam jaringan sel akar, selanjutnya akan memperbanyak hifa eksternal yang berfungsi untuk memperbesar bidang serapan air dan unsur hara.

Hasil penelitian Sasli

(2004)

menunjukkan bahwa pemberian jamur mikoriza dapat meningkatkan pertumbuhan bibit kakao yang lebih baik dibanding bibit tanpa mikoriza, yang terlihat dari tingginya nilai rata-rata untuk hampir semua peubah yang diamati dibanding bibit yang tidak bermikoriza. Aplikasi mikoriza 
meningkatkan pertambahan tinggi tanaman dibandingkan dengan kontrol.

Hasil penelitian Karnedi (2017) menunjukan bahwa tingkat infeksi CMA yang tinggi pada akar tanaman akan memudahkan akar tanaman dalam menyerap unsur-unsur hara yang penting bagi pertumbuhan. Ketebalan dan panjang akar akan memperluas ruang permukaan penyerapan unsur hara yang berada di sekitar perakaran. Menurut Iskandar (2002), prinsip kerja dari mikoriza ini adalah menginfeksi sistem perakaran tanaman inang, memproduksi jalinan hifa secara intensif sehingga tanaman yang mengandung mikoriza tersebut akan mampu meningkatkan kapasitas dalam penyerapan unsur hara. Selanjutnya, Iskandar (2002) mengemukakan secara umum manfaat yang diberikan dengan penggunaan pupuk hayati mikoriza adalah meningkatkan penyerapan unsur hara (terutama unsur P). Tanaman yang bermikoriza dapat menyerap pupuk $\mathrm{P}$ lebih tinggi (10-27\%) dibandingkan dengan tanaman yang tidak bermikoriza (0.4-13\%).

Mikoriza juga berperan dalam menstimulus pembentukan hormon-hormon pertumbuhan tanaman, seperti sitokinin dan auksin. Hormon sitokinin dan auksin ini berperan dalam pembelahan dan pemanjangan sel, sehingga menyebabkan peningkatan tinggi tanaman (Talanca, 2010). Pertumbuhan akar yang baik akibat inokulasi mikoriza dapat meningkatkan pertumbuhan tajuk melalui tinggi tanaman kopi, diameter batang, dan jumlah daun. Yildiz (2010) menyatakan bahwa pertumbuhan tajuk tanaman mentimun dan tomat yang diberi mikoriza lebih baik dibanding dengan tanaman yang tidak diberi mikoriza. Tanaman yang diberi mikoriza memiliki perakaran yang lebih baik, karena hifa yang berada di luar akar membantu penyerapan unsur hara terutama unsur $\mathrm{P}$ dan air yang dibutuhkan oleh tanaman untuk pertumbuhan.

\section{KESIMPULAN}

Perlakuan dosis mikoriza pada bibit kakao sambung pucuk berpengaruh nyata terhadap semua variabel pengamatan pertumbuhan bibit kakao umur 60 hari setelah aplikasi mikoriza dan dosis mikoriza $50 \mathrm{~g} /$ polybag memberikan hasil tertinggi untuk semua variabel pengamatan.

\section{UCAPAN TERIMA KASIH}

Penelitian ini dapat dilaksanakan karena adanya beberapa pihak yang mendukung kami, untuk itu perkenankanlah kami menyampaikan ucapan terimakasih kepada Pimpinan Fakultas dan Program Studi yang telah memberikan masukan, 
Bolly: Efektifitas penggunaan cendawan mikoriza terhadap pertumbuhan bibit kakao

kritik dan saran kepada penulis serta semua pihak yang telah membantu penyelesaian tulisan ini.

\section{DAFTAR PUSTAKA}

Baharudin dan Rubiyo. 2013. Pengaruh Perlakuan Benih Dan Media Tanam Terhadap Peningkatan Vigor Bibit Kakao Hibrida. Buletin Ristry. Vol. 4 (1): 27-38. https://media.neliti.com/media/public ations/141956-ID-pengaruhperlakuan-benih-dan-mediatanam.pdf

Goenadi, D.H., Baon, J.B., Herman, dan Purwoto,A..2005. Prospek Dan Arah Pengembangan Agribisnis Kakao Di Indonesia. Badan Penelitian Dan Pengembangan Pertanian, Departemen Pertanian:Jakarta

Iskandar, D. 2002. Pengaruh Pupuk Hayati Mikoriza Untuk Pertumbuhan dan Adaptasi Tanah di Lahan Marjinal. [Skripsi]. Fakultas Pertanian. Universitas Riau. Pekanbaru. 58 Hal.

Karnedi (2017). Pengaruh waktu pemberian cendawan mikoriza arbuskular terhadap pertumbuhan koro hijau sebagai tanaman pioner pengembali kesuburan tanah pada tanah bekas tambang kapur. Program studi pendidikan biologi, Universitas Sanata Darma. Yogyakarta.

Limbongan, J., S. Kadir, B. Amiruddin, B. Nappu, dan P. Sanggola.2010. Pengkajian Penggunaan Bahan Tanaman Unggul Menunjang Program Rehabilitas Tanaman Kakao Di Sulawesi Selatan. Laporan Hasil Pengkajian. Balai Pengkajian
Teknologi Pertanian Sulawesi Selatan, Makassar. $23 \mathrm{hlm}$.

Limbongan Jermia dan Djufry Fadjry. 2013. Pengembangan Teknologi Sambung Pucuk Sebagai Alternatif Pilihan Perbanyakan Bibit Kakao. J. Litbang Pert. Vol. 32 (4) : 166-172. https://media.neliti.com/media/public ations/30936-ID-pengembanganteknologi-sambung-pucuk-sebagaialternatif-pilihan-perbanyakanbibi.pdf

Nurbaity, A., Herdiyantoro, D., dan Setiawan, A. 2007. Aplikasi Fungi Mikoriza Arbuskula dan Bahan Organik untuk Meningkatkan Ketahanan Tanaman Jagung terhadap Kekeringan di Kabupaten Bandung. Prosiding Seminar dan Kongres Nasional Masyarakat Konservasi Tanah Indonesia ke VI.

Parapasan, Y. Adryade R, G. Waktu dan Cara Aplikasi Cendawan Mikoriza Arbuskular (CMA) pada Pertumbuhan Bibit Tanaman Kopi. Jurnal Penelitian Pertanian Terapan Vol.13 (3): 203-208 ISSN 14105020.

Prawoto, AA.2008. Perbanyakan Tanaman. Kakao: Manajemen Agribisnis Dari Hulu Hingga Hilir. Swadaya: Jakarta.

Sasli, I. 2004. Peranan Mikoriza Vesikula Arbuskula (MVA) dalam Peningkatan Resistensi Tanaman Terhadap Cekaman Kekeringan. Makalah pribadi Pengantar $\mathrm{Ke}$ Falsafah Sains. Sekolah Pasca Sarjana, IPB.

Sribawanti Putu., Lapanjang Iskandar M., Made Usman. 2016. Pertumbuhan 
Bibit Sambung Pucuk Dini Kakao (Theobroma cacao L.) Klon Sul-1 dan Sul-2 Yang Diberi Pupuk Organik Cair Berbeda Konsentrasi. Agrotekbis. Vol. 4 (3): 267-273. https://media.neliti.com/media/public ations/250368-none-80fe76b0.pdf

Sugiarti, L. dan Yana T,. Pengaruh Pemberian Takaran Fungi Mikoriza Arbuskular (Fma) Terhadap Pertumbuhan Bibit Kopi Arabika (Coffea arabica L.). Jurnal Agro 5(1) 2018.

Wahyudi, T., Panggabean, T.R. dan Pujianto.2008. Panduan Lengkap
Kakao: Manajemen Agribisnis Dari Hulu Hingga Hilir. Penebar Swadaya: Jakarta

Wirawan, G. 2014. "Identifikasi Fungi Mikoriza Arbuskular Secara Mikroskopis pada Rhizosfer Tanaman Alang-Alang”. Skripsi. Universitas Udayana. Vol. 3, No. 4.

Wirawan. G, "Identifikasi Fungi Mikoriza Arbuskular Secara Mikroskopis pada Rhizosfer Tanaman Alang-Alang". Skripsi. Universitas Udayana. 2014. Vol. 3, No. 4. 